\title{
Editorial
}

\section{9/11 World Trade Center Attacks: Lessons in Fire Sufety Engineering After the Collapse of the Towers}

\author{
Guillermo Rein*, Department of Mechanical Engineering, Imperial College \\ London, London, UK
}

Every engineering discipline has been shaken by tragic events at some point. Ralph W. Emerson (1803-1882) wrote that "We learn geology the morning after the earthquake". Humans tend to identify gaps of knowledge after a catastrophe. Over time, progress and modern societies have established the means to set up major independent investigations after a technological disaster strikes. Their objective is to unearth the causes and learn lessons from the event so that similar catastrophes are avoided in future. In order for this to happen, it is essential that the results of the investigations are widely disseminated and that the scientific community carefully analyses them, critically assesses them and further improves the conclusions and lessons. This special issue invites the fire safety engineering community to just do that with respect to the $9 / 11$ attacks on the World Trade Center (WTC) in New York (Figure 1).

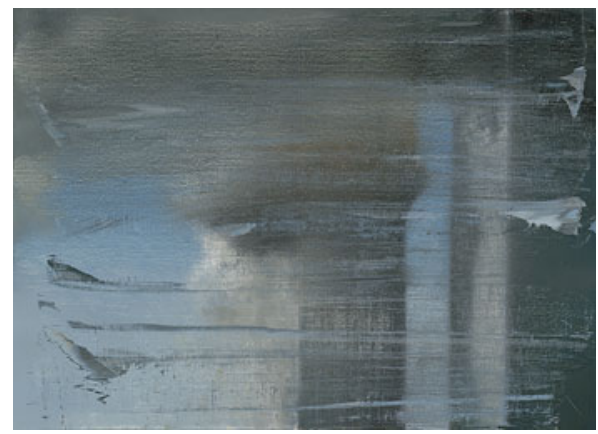

Figure 1. September, painted by Gerhard Ritcher in 2005 (reproduced with license) and currently at MoMA, NY. It is a metaphor of the image imprinted on our memories by presenting a hazy and vague version of the burning towers.

\footnotetext{
* Correspondence should be addressed to: Guillermo Rein, E-mail: g.rein@imperial.ac.uk
} 
WTC towers 1, 2, 5 and 7 collapsed because of the fires triggered by the attacks. From causes to consequences, this disaster touched on a wide range of scientific disciplines. Understanding it thus requires a multidisciplinary approach, and its most important elements are covered in this special issue.

The issue starts with overall layout descriptions of WTC 1, 2 and 7 towers [1] as the setting for the following multidisciplinary contributions. The discipline of solid mechanics was used to study how the airplanes and the subsequent explosions broke through the tower structures [2]. Principles of human behaviour were applied to understand the evacuation of the occupants following the attacks [3, 4]. The aircraft explosions triggered large fires inside both towers - their spread and their intensity were reconstructed using the laws governing fire dynamics [5]. Knowledge of heat transfer and structural mechanics then helped to explain the possible origins and causes of the towers' collapses [6, 7]. Structural mechanics is also helping to design safer buildings and avoid collapse through new engineering design methods [8] and new probabilistic solutions to the problem [9]. Finally, environmental and medical sciences studied the health effects of the airborne emissions from the collapses and subsequent fires (the longest urban fire in modern history - the immense piles of debris smouldered for 5 months) on the emergency responders and the population of New York [10].

A survey of the scientific literature published on the WTC attacks shows the efforts of all these disciplines - the most productive of which has been the community studying the emissions and their health effects. Their work includes a few thousand papers, and several reviews have already been produced to allow for synthesis of findings (the latest one, [10] by Crane et al., is published in this issue). Unfortunately, at the other extreme we find fire dynamics and fire safety engineering, which have been among the least productive, and a review cannot be considered yet because of the paucity of sources to synthesize from (the exception being the topic of evacuation; its first review, [3] by Fahy, is published in this issue). Because fire is the root cause of the collapses, this lack of progress has created a weak spot in the ability of fire safety engineers to explain convincingly to other professionals the events of the disaster, and the lessons to be learnt from them.

This is perhaps best illustrated by an example. In September 2011, 10 years after the attacks, the international magazine Scientific American published an article ("Castles in the Air") on the WTC disaster's effect on the design of new tall buildings. It concluded that high rise buildings needed to be kept away from aircrafts and should have means for prompt evacuation; it did not discuss protection from fire. However, WTC 1, 2, 5 and 7 collapsed because of the fires the attacks had triggered - they had resisted the aircraft impacts (WTC 5 and 7 were not even hit) and most of the occupants below the floors of impact were able to safely evacuate.

It is essential that fire safety science fills the knowledge gaps, and this issue is born to address the need. We want to synthesize here what is currently known about the 9/11 WTC disaster so that we can learn the lessons and let the fire safety community carefully and critically assess them. 


\section{References}

1. McAllister TP, Sadek F, Gross JL, Averill JD, Gann RG (2013) Overview of the structural design of World Trade Center 1, 2, and 7 buildings. Fire Technol 49(3). doi: 10.1007/s10694-012-0285-6

2. McAllister TP, Sadek F, Gross JL, Kirkpatrick S, MacNeill RA, Bocchieri RT, Zarghamee M, Erbay OO, Sarawit AT (2013) Structural analysis of impact damage to World Trade Center buildings 1, 2, and 7. Fire Technol 49(3). doi:10.1007/s10694012-0286-5

3. Fahy RF (2013) Overview of major studies on the evacuation of World Trade Center buildings 1 and 2 on 9/11. Fire Technol 49(3). doi:10.1007/s10694-012-0290-9

4. Day RC, Hulse LM, Galea ER (2013) Response phase behaviours and response time predictors of the 9/11 World Trade Center evacuation. Fire Technol 49(3). doi: $10.1007 / \mathrm{s} 10694-012-0282-9$

5. Gann RG, Hamins A, McGrattan K, Nelson HE, Ohlemiller TJ, Prasad KR, Pitts WM (2013) Reconstruction of the fires and thermal environment in World Trade Center buildings 1, 2, and 7. Fire Technol 49(3). doi:10.1007/s10694-012-0288-3

6. McAllister TP, Gross JL, Sadek F, Kirkpatrick S, MacNeill RA, Zarghamee M, Erbay OO, Sarawit AT (2013) Structural response of World Trade Center buildings 1, 2 and 7 to impact and fire damage. Fire Technol 49(3). doi:10.1007/s10694-012-0289-2

7. Kotsovinos P, Usman A (2013) The World Trade Center 9/11 disaster and progressive collapse of tall buildings. Fire Technol 49(3). doi:10.1007/s10694-012-0283-8

8. Flint G, Lamont S, Lane B, Sarrazin H, Lim L, Rini D, Roben C (2013) Recent lessons learned in structural fire engineering for composite steel structures. Fire Technol 49(3). doi:10.1007/s10694-012-0291-8

9. Guo Q, Shi K, Jia Z, Jeffers AE (2013) Probabilistic evaluation of structural fire resistance. Fire Technol 49(3). doi:10.1007/s10694-012-0293-6

10. Crane MA, Milek DJ, Globina Y, Seifu L, Landrigan PJ (2013) Health effects of the World Trade Center 9/11 disaster: an overview. Fire Technol 49(3). doi:10.1007/ s10694-012-0284-7 